\title{
Catastrophic supply chain disruptions and supply network changes: a study of the 2011 Japanese earthquake
}

\author{
Byung-Gak Son
}

The Business School (formerly Cass), City, University of London, London, UK Sangho Chae

Department of Management, School of Economics and Management, Tilburg University, Tilburg, The Netherlands, and

Canan Kocabasoglu-Hillmer

The Business School (formerly Cass), City, University of London, London, UK

\begin{abstract}
Purpose - Catastrophic supply chain disruptions can significantly damage the operational and financial performance of firms. While a growing body of literature on supply network structures has studied what influences supply networks' vulnerability to supply chain disruptions and capability to recover from them, it remains unclear how supply network structures change after major supply chain disruptions. We aim to provide an understanding of how these changes occur.

Design/methodology/approach - Using a natural experiment approach and supply network data from Factset, this study investigates how firms' supply network structures change after experiencing the catastrophic supply chain disruptions caused by the 2011 Tohoku earthquake and tsunami in Japan. We capture postearthquake supply network changes using the measures of degree centrality and ego network density.

Findings - The results of the analysis suggest that compared to unaffected firms, the affected firms experience changes in their supply network structures tending toward lower complexity measured by in-degree centrality, out-degree centrality and ego network density.

Originality/value - This study contributes to social network theory and the complex adaptive supply network literature by providing empirical evidence of structural changes in supply networks after catastrophic supply chain disruptions. A managerial contribution is made by providing a reflection on why these changes might be occurring and alert firms to the challenges of managing complexity in their supply networks.
\end{abstract}

Keywords Supply networks, Network change, Supply chain disruption, Catastrophic disaster, Complexity Paper type Research paper

\section{Introduction}

Supply chain disruptions can significantly damage the operational and financial performance of firms (Hendricks and Singhal, 2005; Wagner and Bode, 2008). A recent example is the COVID-19 pandemic, where we witnessed critical shortages of pharmaceuticals, key medical supplies and other products due to transportation disruptions, temporary trade restrictions, sick personnel,

(C) Byung-Gak Son, Sangho Chae and Canan Kocabasoglu-Hillmer. Published by Emerald Publishing Limited. This article is published under the Creative Commons Attribution (CC BY 4.0) licence. Anyone may reproduce, distribute, translate and create derivative works of this article (for both commercial and non-commercial purposes), subject to full attribution to the original publication and authors. The full terms of this licence may be seen at http://creativecommons.org/licences/by/4.0/legalcode

The authors are grateful for the valuable comments and suggestions provided by two anonymous reviewers and a guest editor. The authors also thank the seven interviewees for sharing their insights that helped enhance the validity of our findings. Finally, the authors deeply appreciate the time and effort by the EurOMA 2020 Chris Voss Award committee for selecting our paper as one of the finalists.

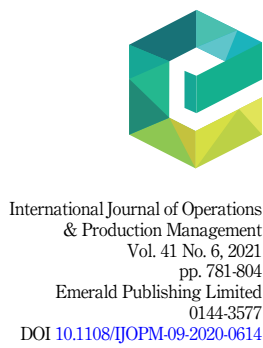


IJOPM 41,6

plant closures and shortages of materials from lower-tier suppliers (Shih, 2020, Van Hoek, 2020). Besides, similar to previous examples such as the Thai flood, changes are expected after COVID19 with respect to the size of the network, supplier locations and the management of the network (Gunessee and Subramanian, 2020; Handfield et al., 2020; Van Hoek, 2020). The vulnerability of the supply chain to shocks significantly reduces its resilience (Pettit et al., 2013, 2019). Supply network structures are an important driver of a firm's vulnerability to disruptions (Kamalahmadi and Parast, 2016; Pettit et al., 2013). The growing body of work on supply network structures offers important contributions to the vulnerability aspect of supply chain resilience (Basole and Bellamy, 2014; Kim et al., 2011, 2015; Wagner and Neshat, 2010).

Research on supply network structures uses social network theory as a theoretical lens, which argues that the structural characteristics of a firm's embeddedness in its networks influence its performance (Adler and Kwon, 2002). Such research goes beyond looking at the cumulative impact of dyadic relationships and focuses on the opportunities and challenges that arise from the complex inter-relationships in the network (Choi and Kim, 2008). Past supply network research has investigated how the structural characteristics of supply networks affect firm performance (Bellamy et al.,2014; Lu and Shang, 2017). Within the context of supply chain disruption, networklevel studies have adopted a complexity perspective in explaining why large, dense supply networks can be vulnerable to external shocks (Bode and Wagner, 2015; Choi and Krause, 2006; Craighead et al., 2007; Hearnshaw and Wilson, 2013; Scheibe and Blackhurst, 2018).

Although there has been significant research on the impact of supply network complexity on supply chain vulnerability and disruption recovery, what still remains unclear is the impact of disruptions, particularly catastrophic disruptions, on supply network structures. Considering that supply network structures determine the amount and quality of resources and knowledge a buying firm can access (Bellamy et al., 2014; Gulati et al., 2000), this is a critical question to be answered. If supply network complexity exposes firms to higher supply chain risks and/or hinder their efforts to manage them, the firms that suffered from major disruptions may attempt to reduce the overall levels of complexity to make their supply chains more resilient by adjusting their supply network structures. To our knowledge, however, no empirical research has focused on the structural changes in supply networks after significant supply chain disruptions. With the exception of Park et al.'s study (2018) on the evolution of supply chain alliance networks, there are few studies empirically exploring how supply network structures change and what drives those changes. In fact, dynamics and patterns of network change are one of the least explored areas in social network theory (Gulati et al., 2000; Madhavan et al., 1998; Suitor et al., 1997; Venkatraman and Lee, 2004).

Building on the literature on social network theory and complex adaptive supply networks, we aim to understand how supply network structures-specifically supply network complexity - change after firms experience catastrophic supply chain disruptions. Therefore, we adopt a natural experiment approach utilizing the difference-in-differences analysis and take the 2011 Tōhoku earthquake and tsunami (henceforth the earthquake) as the research setting for investigating supply network structural changes of the firms affected by catastrophic supply chain disruptions. In line with prior research on supply network complexity and structures, we capture the supply network complexity using the measures of degree centrality and ego network density.

The results from our analysis suggest that firms that faced catastrophic disruptions followed by the earthquake demonstrated reduced levels of supply network complexity, measured by in-degree centrality, out-degree centrality and ego network density, compared to those that were not affected by it. We reflect on why this might be happening as well as the possible consequences of this shift. While research on complexity provides an explanation that this could be seen partly as a correction to the destructive effects of supply network complexity, the new status quo is also likely to bring new risks in terms of the reduced number of direct and indirect network ties and fewer resources to access through them. 
Our study contributes to the fast-growing literature on supply networks by empirically investigating structural changes resulting from catastrophic supply chain disruptions caused by a major natural disaster. In particular, this paper contributes to social network theory by providing new insights into the relatively under-explored area of the dynamics and patterns of network change by initiating a discussion on how the vulnerability exposed by catastrophic supply chain disruptions brings subsequent structural changes in supply networks. We provide empirical evidence that firms experienced adjustments in their supply network structures; some potentially driven by themselves, and others initiated by other companies in their supply networks. Overall, compared to non-affected firms, the firms that experienced major supply chain disruptions have reduced overall levels of complexity in their supply networks.

\section{Theoretical background}

\subsection{Social network theory}

Social network theory seeks to understand an entity, which in our case is the firm, through its web of relationships of a firm has and how it is embedded into them (Borgatti and Ofem, 2010). Social network theory suggests that a firm's embeddedness in its networks influences its performance (Adler and Kwon, 2002). Specifically, its structural embeddedness determines the level of its access to resources and knowledge held by others in the network (Nahapiet and Ghoshal, 1998). As such, a firm's ties with other organizations are often described as capital (Koka and Prescott, 2002), which is a valuable and non-imitable resource (Nahapiet and Ghoshal, 1998) that enhances a firm's competitiveness (Rowley et al., 2000; Son et al., 2016).

Different patterns of a firm's structural embeddedness are related to its competitiveness (Borgatti and Ofem, 2010). The centrality of a firm reflects its relative importance in its supply network (Kim et al., 2011; Dong et al., 2015) such as social status and reputation (Bonacich, 1972). As a company occupies a central location in a network, it will get access to information and resources by others more easily (Bellamy et al., 2014), which will result in various performance advantages such as higher innovation output (Bellamy et al., 2014; Lu and Shang, 2017). Degree centrality, which is one of the centrality measures used in our study, refers to the number of direct links an organization maintains with others in its network (Provan et al., 2007). In a supply network, this metric measures the number of direct suppliers (in-degree centrality) and customers (out-degree centrality) (Borgatti and Li, 2009; Kim et al., 2011, 2015; Shao et al., 2018).

Density is a network-level measure referring to the proportion of the number of the total ties to the number of all possible ties in a network (Autry and Griffis, 2008; Kim et al., 2011). It measures the overall level of connectedness among actors in a network (Autry and Griffis, 2008; Provan et al., 2007). As for ego network density, it refers to the overall level of connectedness among the first-tier partners of the firm (Ahuja, 2000; Skilton and Bernardes, 2015). Dense networks can facilitate communication among the members and lead to network-level social capital (Autry and Griffis, 2008; Gulati and Gargiulo, 1999; Uzzi, 1996). Moreover, focal firms could access additional resources or do information pooling/sharing through the connections of their partners (Choi and Wu, 2009; Wu and Choi, 2005). On the other hand, for individual members, being in a sparsely connected corner of a network can benefit from non-redundant information (Ahuja, 2000; Borgatti and Li, 2009; Granovetter, 1973, 1983; Burt, 2004), which is critical in innovation creation (Ahuja, 2000; Burt, 2004).

\subsection{Supply chain vulnerability from a supply network complexity perspective}

A supply chain disruption refers to an unanticipated event that disrupts the normal flow of goods within a supply chain (Craighead et al., 2007). The damaging nature of supply chain disruptions has motivated researchers to investigate how a firm can build supply chain resilience, defined as the capability to withstand and recover from supply chain disruptions (e.g. Kleindorfer and Saad, 2005; Wagner and Bode, 2006). 
IJOPM 41,6

784

The vulnerability of the supply chain of a firm makes it sensitive to disruptions, thereby reducing its resilience (Pettit et al., 2010, 2013; Sheffi and Rice, 2005). The scale of its supply network can be a significant driver of a firm's vulnerability (Blackhurst et al., 2011; Pettit et al., 2013). Moreover, the vulnerability of the individual companies in the supply network has a knock-on effect in that "the failure of any one element in it could cause the whole network to fail" (Rice and Caniato, 2003, p. 22). Even a relatively minor disruption can increase in magnitude as it propagates throughout the supply chain (Scheibe and Blackhurst, 2018; Blackhurst et al., 2011).

More recent research has aimed at pinpointing what exactly about the network structure creates this vulnerability, using social network theory, and more specifically, the concept of supply network complexity (Kim et al., 2015). A complex system is "one made up of a large number of parts that interact in a non-simple way" (Simon, 1962, p. 468), for which a supply network is a good example (Pathak et al., 2007).

The complexity perspective proposes that a firm having an excessive number of ties with other companies and the inter-relationships between these companies could potentially both become a gateway for the propagation of disruptions and hinder an effective disruption response (Basole and Bellamy, 2014; Bode and Wagner, 2015; Choi and Krause, 2006; Chowdhury and Quaddus, 2017; Craighead et al., 2007; Kim et al., 2015; Scheibe and Blackhurst, 2018). Influential studies based on the complexity perspective (e.g. Choi and Krause, 2006; Kim et al., 2015) have used the NK model (Kauffman and Levin, 1987; Levinthal, 1997) to measure supply network complexity, where $N$ represents the number of suppliers of a focal firm and $K$ represents the inter-relationships among them. In the context of this study, these correspond to the degree centrality and density metrics in social network theory (Kim et al., 2011).

Past studies have suggested that the more central a firm is, the more likely it is to experience a supplier induced disruption (Bode and Wagner, 2015; Chaturvedi and Martínezde-Albéniz, 2011; Perrow, 1984). Moreover, the number of network ties is positively related to the level of transaction intensity a focal firm faces (Bode and Wagner, 2015; Choi and Krause, 2006; Powell et al., 2005) and can result in a high level of operational burden for the firm (Bode and Wagner, 2015; Borgatti and Li, 2009; Kim et al., 2011, 2015; Wiedmer et al., 2021). Thus, the size of the supply base impacts the extent of effort the focal firm would have to expend to coordinate its supply chain in response to a disruption. Consequently, a firm's ability to manage supply chain risk and/or respond to disruptions decreases as the number of supply chain partners increases (Bode and Wagner, 2015).

With regard to density, there have been arguments for both positive and negative links between network density and vulnerability (Choi and Krause, 2006; Kim et al., 2015). On the one hand, a denser network could be more resilient to the removal of one of these links (Janssen et al., 2006). On the other hand, dense networks can propagate the impact of a supply chain disruption across the supply network and increase the systematic risk in the network (Scheibe and Blackhurst, 2018). In addition, a high number of inter-relationships can increase the coordination costs of network-wide disruption recovery efforts (Bode and Wagner, 2015; Craighead et al., 2007).

Past studies have investigated how supply network complexity affects the likelihood of disruption propagation and efforts to recover from such disruptions. However, to our knowledge, there is no research to date that investigates how the complexity of firms' supply networks change after experiencing such disruptions. We aim to contribute to this underexplored question around the dynamic nature of supply networks, which we discuss in the next section.

\subsection{Structural changes of supply networks}

Changes in networks and related dynamics form one of the least explored areas in social network theory (Gulati et al., 2000; Madhavan et al., 1998; Suitor et al., 1997; Venkatraman and 
Lee, 2004). This is probably a consequence of early network research where it was assumed that a network structure is a "given" rather than deliberately created by its members (Nohria and Eccles, 1992) and that these structures persist over time (Burkhardt and Brass, 1990; Doreian, 1986). Similarly, most empirical research on supply networks has also mostly taken a static view, with a limited focus on the evolution of network structure (Park et al., 2018).

Inter-firm networks including supply networks, however, are dynamic (Gulati et al., 2000; Park et al., 2018). This is because inter-firm networks are critical in providing firms with access to resources and knowledge they do not possess (Gulati et al., 2000) and those networks need to be restructured in line with the changing needs of firms and the external environment (Walker et al., 1997; Zaheer and Soda, 2009). Companies can be compelled or forced to modify the structure of their networks as a response to major external shocks (Li et al., 2010; Madhavan et al., 1998) and strive to maintain access to knowledge and resources through their networks and beyond. For example, the advent of new technology often encourages or forces firms to venture out of their usual networks to create ties with new firms in order to access novel knowledge and innovation (Bellamy et al., 2014; Borgatti and Li, 2009; Li and Rowley, 2002). Other examples of external shocks that lead to changes in network structures are regulatory changes and the entry of a powerful competitor (Madhavan et al., 1998; Li et al., 2010).

In the supply chain management context, the literature on complex adaptive supply networks has been focusing on structural adaptations of supply networks. While the studies in this stream of the literature offer profound insights on adaptivity in supply networks, most studies rely on conceptual development (e.g. Choi et al., 2001; Kauffman et al., 2018; Pathak et al., 2007), simulation (e.g. Giannoccaro et al., 2018; Kim et al., 2015) and conceptual case studies (e.g. Nair et al., 2016). Large-scale empirical studies in this stream of the literature have considered network structures as predictors of other outcomes such as resilience (Wiedmer et al., 2021), greenhouse gas emissions (Dooley et al., 2019) and resource flows (Sawaya et al., 2015). However, little empirical research on supply networks has examined supply network structural changes as outcomes of external shocks such as catastrophic supply chain disruptions. This dearth of large-scale empirical studies on supply network structural changes may originate from the limited availability of longitudinal supply network data. From the complexity perspective and utilizing archival supply network data, our study seeks to fill this gap in the literature on social network theory and complex adaptive supply networks.

\section{Hypothesis development}

This paper investigates whether the catastrophic supply chain disruptions caused by the earthquake led to structural changes in the affected firms' supply networks. In the following paragraphs, we hypothesize that the supply network complexity of affected companies will diminish after such catastrophic disruptions, both as a result of their actions and those of their partners, and the business environment. In line with past studies that adopt the NK model to conceptualize supply network complexity (Choi and Krause, 2006; Kim et al., 2015; Simon, 1962), we capture supply network complexity through the focal firm's centralityboth in-degree and out-degree centrality to capture the supplier and customer sides, respectively - and its ego network density.

Social network theory suggests that in-degree centrality dictates the level of influence a firm has in its network and the resources it could access through its partners (Bellamy et al., 2014; Borgatti and Li, 2009; Provan et al., 2007). However, the high number of suppliers increases the frequency and complexity of transactions for the buying firm, creating various operational pressures (Bode and Wagner, 2015; Kim et al., 2011, 2015). This would suggest that high in-degree centrality could undermine a firm's efforts to respond to a supply chain disruption. If, as suggested by previous research, the complexity of its supplier network
Catastrophic supply chain disruptions 
IJOPM 41,6

impeded a firm's efforts to respond to a recent catastrophic disruption effectively, the firm could attempt to reduce the number of suppliers and rationalize the size of its supply base after the disruption.

Furthermore, the firm's existing ties with other companies can become a gateway for the propagation of an upstream disruption (Bode and Wagner, 2015; Borgatti and Li, 2009; Kim et al., 2015; Han and Shin, 2016). When considering the dimension of network complexity that focuses on the number of the companies in a supply network (Bode and Wagner, 2015; Kim et al., 2015), in-degree centrality indicates the likelihood of the buying firm being impacted by the propagation of an upstream disruption originated from these suppliers (Bode and Wagner, 2015; Chaturvedi and Martínez-de-Albéniz, 2011). Therefore, a firm that has recently experienced a disruption of this nature is more likely to be driven to streamline its supply base.

Finally, firms are constantly on the lookout for new suppliers that can provide quality components and services as well as new knowledge and innovation (Wagner, 2012; Yan et al., 2020). This activity of adjusting the network needs to be supported by a munificent environment (Koka et al., 2006) as well as the firms' own resources. A major natural disaster reduces environmental munificence by depleting structural, infrastructural and financial resources. Moreover, responding to catastrophic supply chain disruptions requires a company-wide resource mobilization, relegating other needs of the firm, including tie creation, to a secondary position. Thus, reduced environmental munificence and available firm resources will slow down a buying firm's activities of discovering new capable suppliers. For these reasons, we hypothesize that:

H1. Firms that experience catastrophic supply chain disruptions will have fewer suppliers after the disruption, compared to the firms that do not experience the disruption.

Similar to the buying firms that would attempt to reduce their supply network complexity by reducing their number of suppliers after experiencing catastrophic disruptions, customers of affected firms may also attempt to reduce complexity by streamlining their supply networks. This is partially due to the propagation effect discussed earlier. If a firm is affected by supply chain disruption, that disruption will be propagated to some, if not all of its customers (Han and Shin, 2016). Therefore, the firms that are known to have been affected by a major disruption could face difficulties in keeping some existing customers and attracting new ones, at least temporarily.

Furthermore, even if customers prefer to continue their relationship with the focal firm, the impact of the disruption on the financial health of the customers may make it untenable. Disruptions tend to lead to a number of unplanned expenses and restrict access to financial resources, which can lower customers' liquidity and cash reserves. Simultaneously, customers can experience higher levels of demand uncertainty themselves. Catastrophic natural disasters are, therefore, often accompanied by a reduction in customer demand (Park et al., 2013). In terms of attracting new customers, firms may face another challenge. Firms face significant pressures to grow by acquiring more customers. Growing the customer base and maintaining it, however, requires a firm to have the resources, either within its own corporate boundaries or accessible through its business environment (Koka et al., 2006). As discussed earlier, a major natural disaster and the ensuing catastrophic supply chain disruption tend to deplete the internal and external resources necessary to support creating new ties. Therefore, we hypothesize:

H2. Firms that experience catastrophic supply chain disruptions will have fewer customers after the disruption, compared to the firms that do not experience the disruption. 
A dense ego supply network with many inter-relationships among the focal firm's supply chain partners can expose the focal firm to a high level of supply risk (Choi and Krause, 2006). For example, when a system or industry level disruption such as the earthquake increases demand and/or supply volatility, multiple companies in the same network simultaneously rush to secure alternative supply. In a dense network, this could lead to resource cannibalization, where a supplier's capacity that could have been allocated to the focal firm's demand is directed to other players in the focal firm's network (Lee et al., 1997). Similarly, in a tightly connected supply network, an accident at a supplier can disrupt a focal firm's operations both directly and indirectly through other buying firms who also supply to the focal firm (Scheibe and Blackhurst, 2018). Such indirect supply chain disruption propagation is more pronounced in supply networks where several of the buying firm's supply chain partners are connected (i.e. higher ego network density).

In addition, responding to a supply chain disruption requires extensive coordination between a buyer and its supplier for collective sense-making (Johnson et al., 2013; Krause et al., 2007) and resource mobilization (Ambulkar et al., 2015; Olcott and Oliver, 2014). Responding to catastrophic supply chain disruptions may sometimes require joint efforts at the network-level (Olcott and Oliver, 2014). When such extensive efforts are required, connections among the focal firm's supply chain partners can come at additional coordination costs for the firms involved (Choi and Krause, 2006; Choi and Wu, 2009; Craighead et al., 2007). This would be especially true for large companies with a high number of supply chain partners. The consequence of experiencing these coordination costs during the recovery period is likely to put downward pressure on ego network density (see Figure 1).

After experiencing a major supply chain disruption, firms would realize the dangers of indirect disruption propagation and challenges of coordinating during recovery in densely connected supply networks. Therefore, firms with recent experience of a catastrophic supply chain disruption would be expected to simplify their networks. If several firms that are directly or indirectly connected to the focal firm decide to reduce their number of direct ties, the cumulative effect of these firm-level decisions should also lower the ego supply network density for the focal firm. Therefore, we hypothesize:
Catastrophic supply chain disruptions

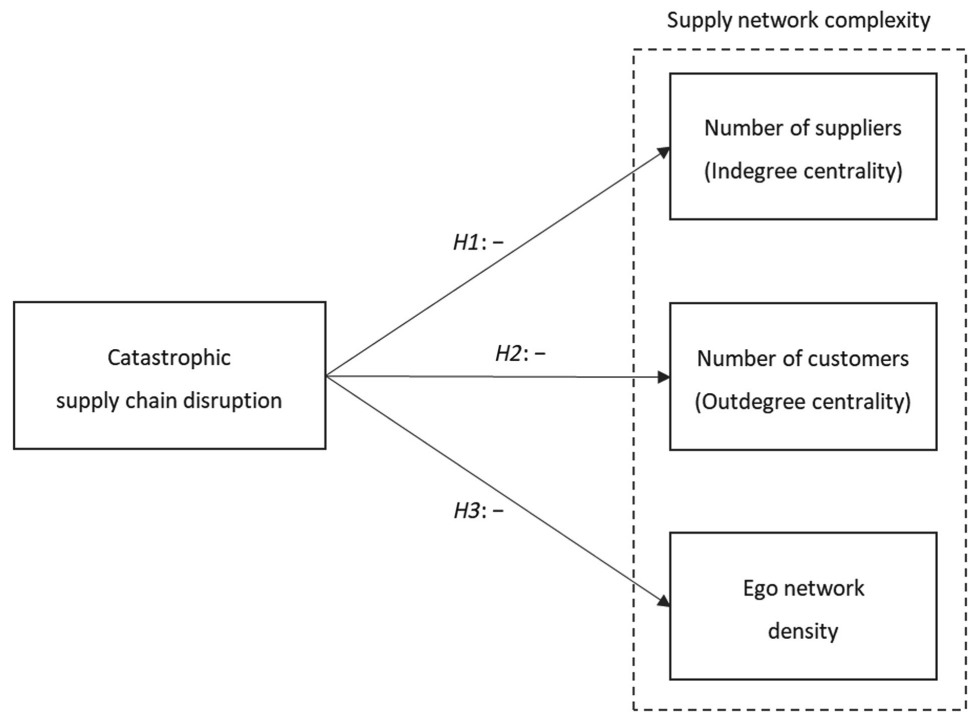

Figure 1. Conceptual model 
IJOPM 41,6
H3. Firms that experience catastrophic supply chain disruptions will have lower ego supply network density after the disruption, compared to the firms that do not experience the disruption.

\section{Methodology}

\subsection{Empirical setting and data}

In this paper, we seek to explore how firms' supply networks change following catastrophic supply chain disruptions. For this, we selected the earthquake as an exogenous force that drives structural changes in supply networks. One useful approach to understanding exogenous factors' impact on structural changes of a network is to consider "occasions for structuring" (Barley, 1986). This approach assumes that exogenous factors can be captured through a specific event that affects network structures. This event needs to be a major shock that disturbs the competitive landscape on a large scale with lasting impact (Barley, 1986; Madhavan et al., 1998).

This paper investigates the 2011 Tōhoku earthquake and tsunami in Japan as a major disaster that serves as an occasion for restructuring the supply networks of affected firms. The reason for selecting the earthquake is that it is considered the "single largest and broadest natural disaster in recent times" causing significant, catastrophic supply chain disruptions and consequently, operational and financial damage to multiple firms operating in Japan (Sheffi, 2015, p. ix), and, therefore, is more likely than smaller-scale events to impact supply network structures.

To build our sample, we used as our starting point the 2011 Forbes Global 2,000 list, which captures the world's largest public companies. Next, using the Global Industry Classification Standard (GICS), we excluded firms from service sectors such as finance, banking and insurance, leaving 934 firms in our initial sample from nine sectors as described by the Forbes Global industry list. These sectors include consumer discretionary, consumer staples, energy, healthcare, industrials, information technology, materials, telecommunications and utilities. The financial data of the 934 initial sample firms were collected from the Orbis database.

Furthermore, we used the FactSet supply chain relationship database to identify these firms' supply network structures. This database comprises records of contractual buyersupplier relationships of more than 30,000 companies compiled from their financial regulatory filings (e.g. 10-K reports) (FactSet, 2021). Using this database, we constructed a network for each firm that consists of their customers and suppliers, the customers' customers and suppliers, and the suppliers' customers and suppliers. Although FactSet does not provide exhaustive lists of customers and suppliers of the firms in the database, its coverage of major customers and suppliers is significantly better than other well-known databases such as the Compustat operations segment (Wang et al, 2020), and recent empirical studies have been using it to investigate the role of supply network structural characteristics in risk management (Wang et al., 2020) and innovation (Chae et al., 2020).

\subsection{Measures}

Based on the networks, we calculated the in-degree centrality, out-degree centrality and ego network density for each firm. We measured each of these variables as follows: In-degree centrality was captured by a count of the first-tier suppliers, whereas out-degree centrality was measured as the total number of direct customers (Kim et al., 2011). Ego network density was calculated as the ratio of the sum of the number of existing relationships between the focal firm and its supply chain partners as well as those between the partners to the total number of all possible relationships between these supply chain network members (Kim et al., 2011). We calculated these variables using UCINET 6.3. One point to note for ego network 
density is that UCINET calculates network density by using the ratio explained above and multiplying this number by 100 . These three network measures were subsequently used to calculate the dependent variables of our study, which are explained in the following section.

We used industry sector dummy variables and pre-earthquake (2010) financial variables (log of total assets, log of the number of employees, log of inventory, return-on-assets, costof-goods-sold-to-sales, cash-to-sales and debt-to-equity) to control for industry and firmspecific factors. The variables were also used during the process of propensity score matching, which is explained in more detail in Section 4.3. In addition, we included the preearthquake in-degree centrality, out-degree centrality and ego network density to control for the initial network structures. These network measures are different from the dependent variable measures, which are explained in the following subsection. Table 1 presents the descriptive statistics and pairwise correlations between the variables. The mean variance inflation factor of the independent and control variables was 1.75 (maximum: 3.20, minimum: 1.01).

\subsection{The difference-in-differences approach}

To capture the changes in supply network structures after the earthquake, we computed the differences between pre- and post-earthquake supply network variables ( $\Delta$ In-degree centrality, $\Delta$ Out-degree centrality and $\Delta$ Ego network density). The differences were computed by subtracting the values of supply network variables measured one year prior to the earthquake (2010) from the values of the same variables measured one year after the earthquake (2012). These differenced measures were used as the dependent variables.

Afterward, we compared these dependent variables of the firms in the treatment group (the Japanese firms affected by the earthquake) with those of the firms in the control group (the firms not affected by the earthquake but with characteristics similar to the treatment group). We explain our process in the next sections.

Treatment group: From the initial sample of 934 Forbes Global 2000 firms, we selected those in the treatment group based on two criteria. First, they have headquarters in Japan. Second, these firms experienced the earthquake in 2011 and reported consequential operational damages in their annual reports at the end of the same fiscal year. We downloaded the 2011-2012 annual reports from Thomson Reuters ONESOURCE. We identified 76 Japanese firms that experienced operational damages from the earthquake and assigned all these 76 firms to the treatment group. As a visual example of the impact of the earthquake, Figure 2 shows the ego supply network diagrams of two companies in the treatment group before (2010) and after (2012) the earthquake.

Establishing the control group using propensity score matching: We employed propensity score matching to construct a sample of control group firms that did not report operational damages caused by the earthquake and have industry- and firm-level characteristics similar to the treated firms. These control group firms were selected from the 934 initial sample firms. The propensity score matching procedure calculates the conditional probability of assignment to the treatment group using the probit estimation with observed covariates (Rosenbaum and Rubin, 1983). The calculated probabilities from the probit estimation, the propensity scores in this context, are then used to determine the similarities between the characteristics of the treated and untreated observations. Typically, an untreated observation that has the nearest propensity score to a treated observation is assigned to the control group.

As discussed earlier, structural changes of a supply network can be induced by exogenous forces as well as endogenous forces and past network characteristics (Gulati et al., 2000; Zaheer and Soda, 2009). This means that it is necessary that the firms in the treatment and control groups have similar ego supply network structures before the earthquake. We used
Catastrophic supply chain disruptions 
IJOPM
41,6

790

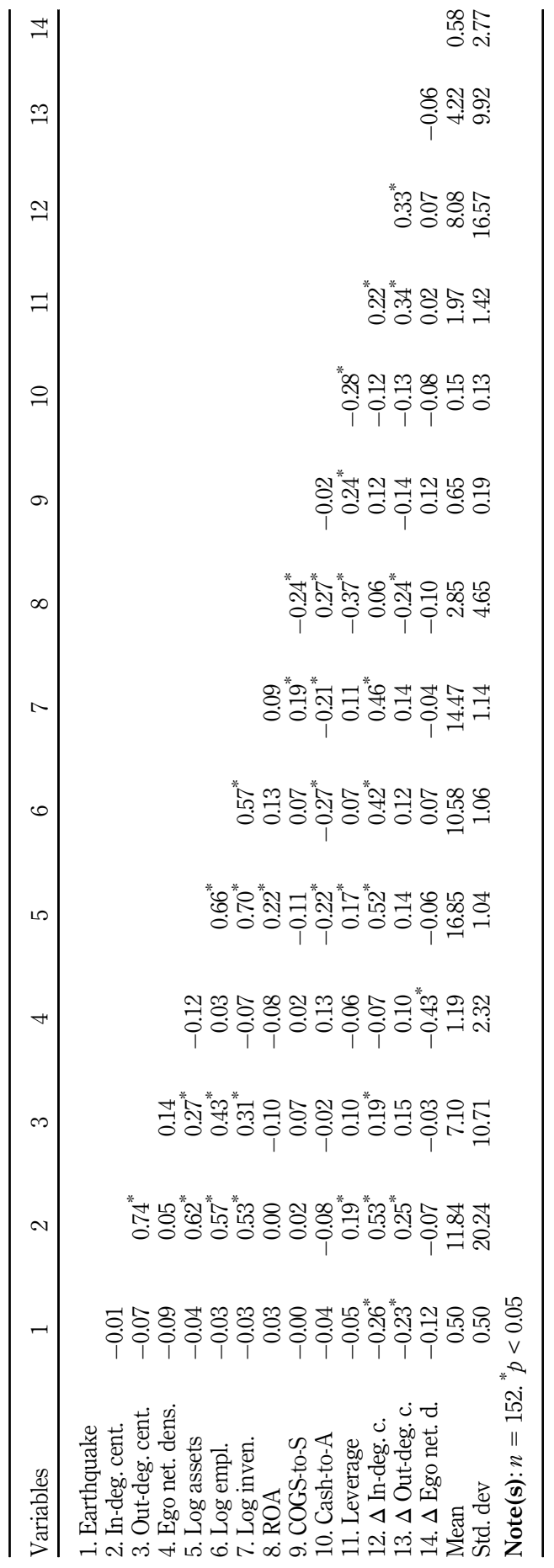

Table 1.

Correlations and descriptive statistics 

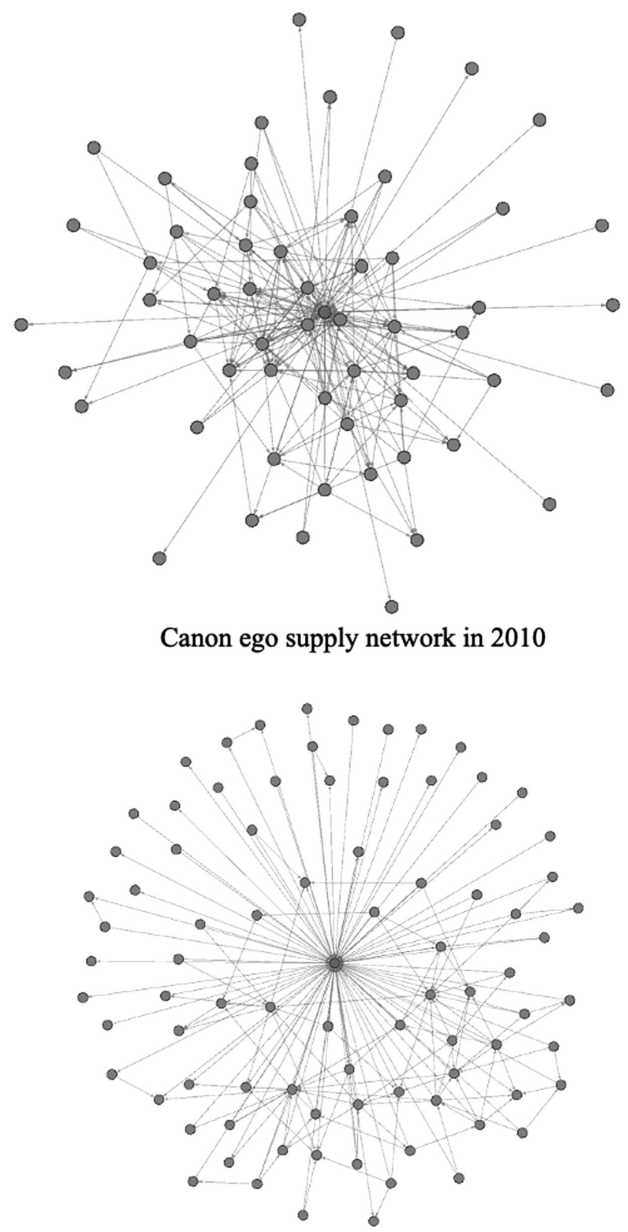

NEC ego supply network in 2010

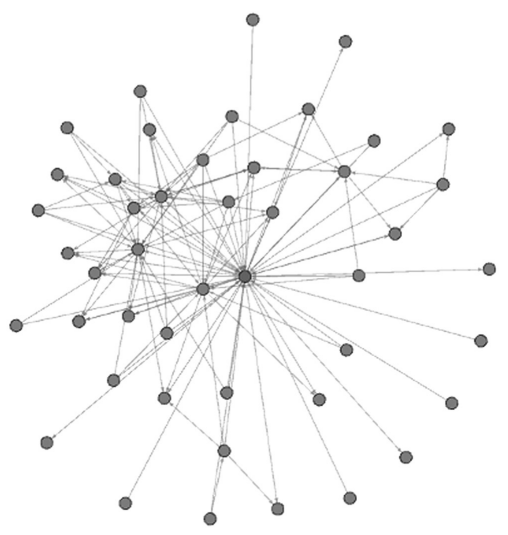

Canon ego supply network in 2012

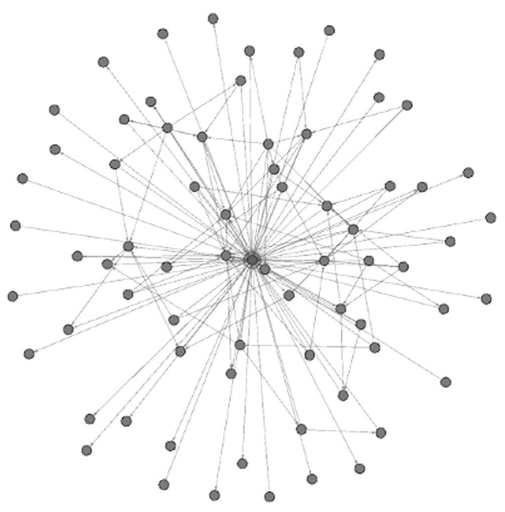

NEC ego supply network in 2012
Catastrophic supply chain disruptions
Figure 2. Ego supply networks before and after the earthquake

the number of suppliers, number of customers and ego network density measured in 2010 for selecting control firms that share similar network characteristics with treated firms.

In addition, we used industry sector dummy variables and pre-earthquake (2010) financial variables (log of total assets, log of the number of employees, log of inventory, return-onassets, cost-of-goods-sold-to-sales, cash-to-sales and debt-to-equity) as additional matching criteria. The economics and finance literature commonly uses these financial variables as matching criteria (e.g. Almeida et al., 2012). Each firm in the treatment group is matched with one control firm that has the nearest propensity score to the treated firm, yielding the final sample of 152 firms. Table 2 shows that there are no significant mean differences between the treatment and control groups in terms of matching characteristics.

Statistical model: We indicate differences between pre- and post-earthquake supply network variables ( $\Delta$ In-degree centrality, $\Delta$ Out-degree centrality and $\Delta$ Ego network density) as $\Delta$ Network $_{i}$ and set up the following regression equation to estimate the impact of the earthquake on the supply network structure: 


\begin{tabular}{|c|c|c|c|c|c|}
\hline \multirow{5}{*}{$\begin{array}{l}\text { IJOPM } \\
41,6\end{array}$} & Matching characteristics & Group & Observations & Mean & $p$-value ( $t$-test) \\
\hline & In-degree centrality & Treatment & 76 & 11.66 & 0.97 \\
\hline & & Control & 76 & 12.01 & \\
\hline & Out-degree centrality & Treatment & 76 & 6.36 & 0.39 \\
\hline & & Control & 76 & 7.84 & \\
\hline \multirow{10}{*}{792} & Ego network density & Treatment & 76 & 0.97 & 0.25 \\
\hline & & Control & 76 & 1.40 & \\
\hline & Log assets & Treatment & 76 & 16.82 & 0.66 \\
\hline & & Control & 76 & 16.89 & \\
\hline & Log employees & Treatment & 76 & 10.55 & 0.74 \\
\hline & & Control & 76 & 10.61 & \\
\hline & Log inventory & Treatment & 76 & 14.43 & 0.68 \\
\hline & & Control & 76 & 14.51 & \\
\hline & Return-on-assets & Treatment & 76 & 2.97 & 0.75 \\
\hline & & Control & 76 & 2.73 & \\
\hline \multirow{6}{*}{$\begin{array}{l}\text { Table } 2 \text {. } \\
\text { Comparison of } \\
\text { matching } \\
\text { characteristics } \\
\text { between treatment } \\
\text { and control groups }\end{array}$} & COGS-to-sales & Treatment & 76 & 0.65 & 0.97 \\
\hline & & Control & 76 & 0.65 & \\
\hline & Cash-to-assets & Treatment & 76 & 0.15 & 0.61 \\
\hline & & Control & 76 & 0.16 & \\
\hline & Leverage & Treatment & 76 & 1.90 & 0.52 \\
\hline & & Control & 76 & 2.05 & \\
\hline
\end{tabular}

$$
\Delta \text { Network }_{i}=\beta \times \text { Earthquake }_{i}+\gamma^{\prime} X_{i}+\varepsilon_{i},
$$

where $i$ indicates the firm and Earthquake is a binary variable that equals one for the treatment group and zero for the control group. $X$ is the vector of control variables explained

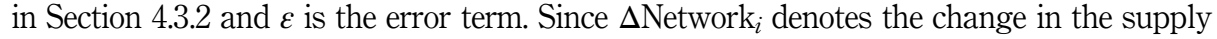
network structure after the earthquake, the sign of the regression coefficient $\beta$ effectively indicates whether the change for the treatment group is positive or negative compared to that for the control group.

\section{Results}

\subsection{Main results}

Table 3 shows the impact of the earthquake on the three dependent variables: $\Delta$ In-degree centrality, $\Delta$ Out-degree centrality and $\Delta$ Ego network density. Models 1, 3 and 5 are base models with control variables only, while Models 2, 4 and 6 include the treatment variable, Earthquake. The significant negative coefficients for Earthquake in Model $2(\beta=-9.63$, $p<0.001)$, Model $4(\beta=-3.49, p=0.003)$ and Model $6(\beta=-0.91, p=0.034)$ provide support for $\mathrm{H} 1, \mathrm{H} 2$ and $\mathrm{H} 3$, respectively. These results suggest that, compared to the firms in the control group, the firms which were affected by the earthquake had reduced levels of indegree, out-degree and ego network centralities. Figure 3 provides a visual representation of the effects of the earthquake on in-degree centrality, out-degree centrality and ego network density. The three dotted lines in Figure 3 show the average differences in the network measures between the treated and control firms. Compared to the control firms (the baseline of zero in the $y$-axis), the treated firms on average had significant declines in the three network measures between the end of 2010 and the end of 2012 .

\subsection{Robustness checks and post hoc analysis}

To check whether our findings are robust to using different time lags in calculating the dependent variables, we computed alternative measures of the dependent variables by 
IJOPM 41,6

\section{4}

Figure 3.

Average network measure differences between treatment and control groups

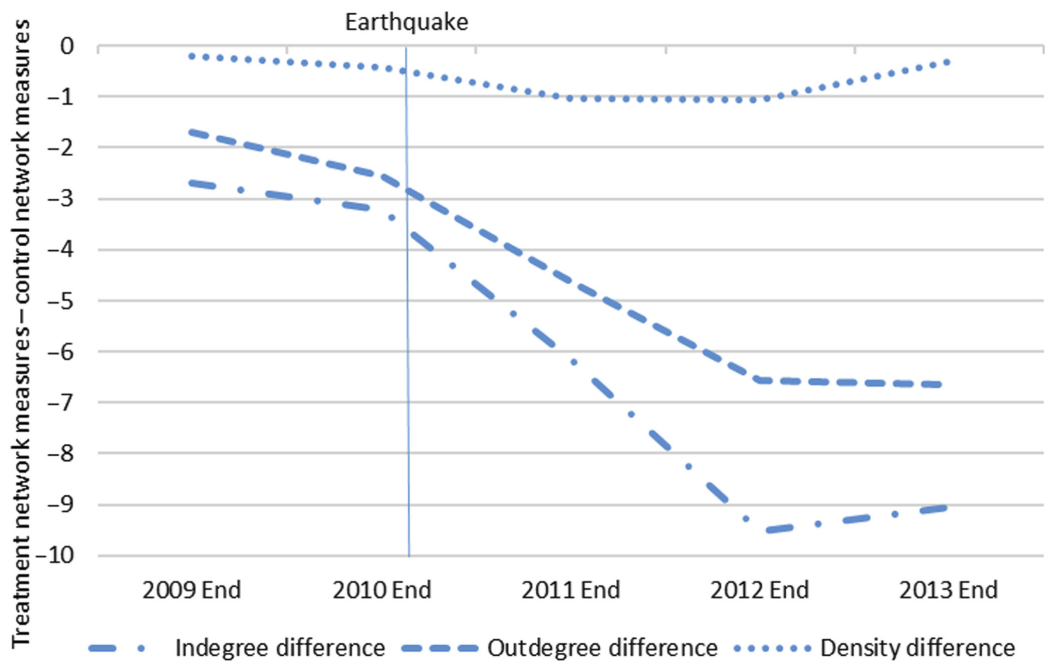

subtracting the values of the network structure variables measured in 2010 from those measured in 2011 and 2013. The results from Models 7 through 11 in Table 4 are consistent with the main results that support $\mathrm{H} 1$ and $\mathrm{H} 2$. However, the non-significant coefficient for Earthquake in Model $12(\beta=-0.16, p=0.691)$ suggests that two years after the earthquake, the firms that were affected by it did not have reduced levels of ego network centrality compared to the firms in the control group. Therefore, we conclude that $\mathrm{H} 3$ is only partially supported.

In addition, to ensure that the differences in the dependent variables between treatment and control groups are not driven by a pre-existing trend before the earthquake in 2011, we tested whether the two groups had parallel trends in 2009 and 2010. For this pre-earthquake parallel trend analysis, we computed the differences in the three dependent variables $(\Delta I n$ degree centrality, $\Delta$ Out-degree centrality and $\Delta$ Ego network density) by subtracting 2009 values from 2010 values. Table 5 shows that there are no statistically significant differences between the treatment and control groups (i.e. non-significant coefficient for treatment) in the three dependent variables measured before the earthquake. This result indicates that the two groups had similar trends in in-degree centrality, out-degree centrality and ego network density prior to the earthquake and strengthens the evidence that the differences between treatment and control groups after the earthquake are caused by the earthquake.

Finally, as a post hoc analysis, we examined how the proportion of Japanese suppliers and customers changed for the treated firms after the earthquake. Comparing tie strengths before and after the earthquake would have been an ideal approach for revealing the importance of "bridging ties" with close buyer-supplier relationships in post-disruption supply network restructuration. However, due to the lack of data on tie strengths, we checked whether the Japanese firms affected by the earthquake increased or decreased the proportion of the suppliers and customers in the same country as an indirect way of measuring closer or more distant buyer-supplier ties. The analysis shows that in the treatment group, the average proportion of Japanese suppliers increased from 2.96\% in 2010 to $7.66 \%$ in 2012 and that of Japanese customers also increased from $7.56 \%$ in 2010 to $8.37 \%$ in 2012 . This result implies that firms that experienced catastrophic supply chain disruptions tend to prefer closer buyer-supplier ties, supporting our theoretical argument that firms will reduce supply network complexity in restructuring their networks after the disruptions. 


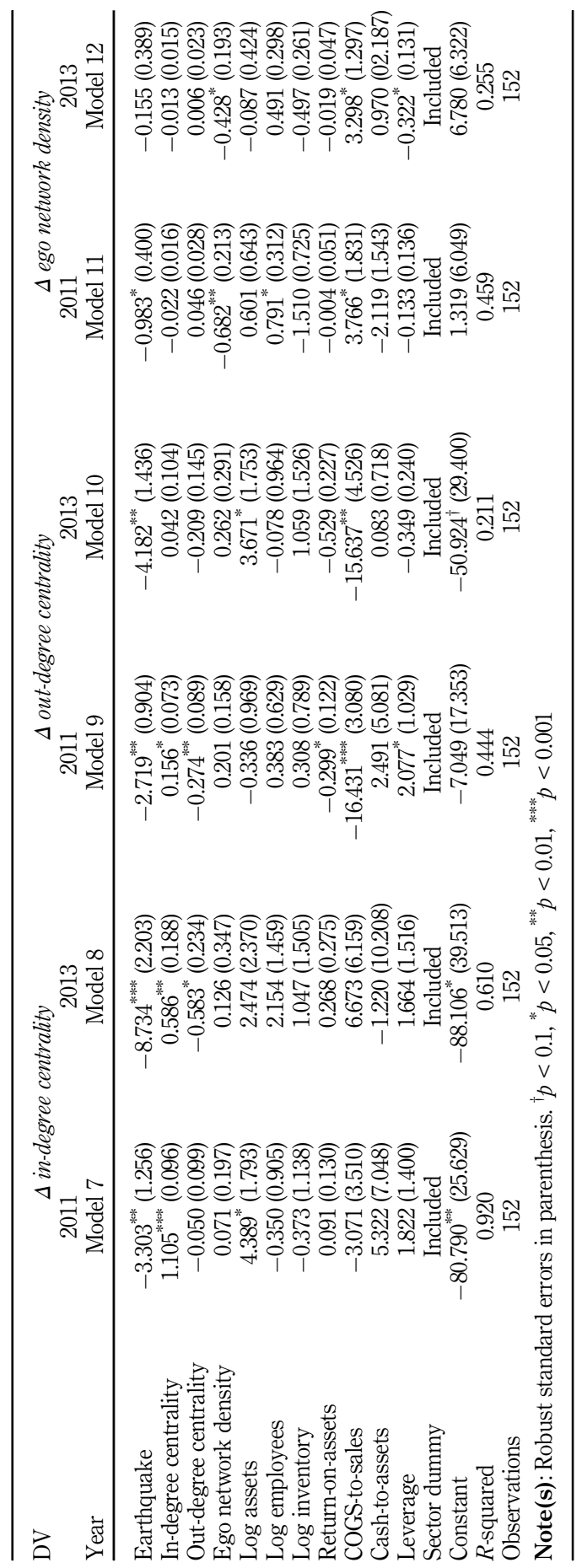

Catastrophic supply chain disruptions

795

Table 4. Robustness checks 
IJOPM 41,6

796

\section{Discussion}

\subsection{Theoretical contributions}

Our paper contributes to the supply network and complex adaptive supply network literature by investigating whether catastrophic supply chain disruptions caused by the 2011 Tōhoku earthquake and tsunami, led to significant structural changes in the supply networks of the affected companies. It has been suggested that complex network structures make the supply chain more vulnerable, and therefore, complexity has generally been considered a barrier to responding to disruptions effectively (e.g. Bode and Wagner, 2015; Choi and Krause, 2006; Scheibe and Blackhurst, 2018). The question of how supply network structures change after major supply chain disruptions has remained unanswered.

Our analysis shows that the firms that were disrupted by the earthquake have seen a reduction in the number of their suppliers (i.e. less complex upstream supply networks) compared to the firms that were not. Previous research on supply network complexity and supply chain vulnerability has established that a relatively simpler supply network structure would (1) have a lower likelihood of upstream disruptions being propagated to the buying firm (Bode and Wagner, 2015; Perrow, 1984) and (2) enhance the buying firm's recovery efforts through less coordination burden with its suppliers (Bode and Wagner, 2015; Borgatti and Li, 2009; Kim et al., 2011, 2015). Our results suggest that after firms experience catastrophic supply chain disruptions, they also witness changes in their supply network structures tending toward lower complexity. We also reason that is this change was imposed upon them by their supply chain partners or the new reality of the business environment. Although we cannot distinguish the exact drivers, what is clear is that, in our sample, there is a shift toward less complex supply chain structures. Our results also extend the debate between complexity and redundancy perspectives. The redundancy perspective in supply chain resilience research postulates that having a larger number of suppliers can be beneficial for the buying firm in responding to a disruption, since the larger the supplier base, the higher the likelihood of finding needed capacity and capability among its suppliers, thereby offering some flexibility (Chowdhury et al, 2019; Johnson et al., 2013; Hearnshaw and Wilson, 2013; Sheffi and Rice, 2005). If that was the case, we would expect to see an increase in postdisruption supplier numbers as a redundancy mechanism. We did not find support for this argument, but our findings do not necessarily suggest the dominance of the complexity perspective over the redundancy perspective.

In order to explore this finding, we conducted seven post hoc interviews with supply chain and procurement practitioners by asking if their companies considered restructuring their supply bases after experiencing a catastrophic supply chain disruption including the earthquake and the COVID-19 pandemic. The responses showed a more nuanced thinking rather than a direct increase or reduction in supply network ties. For example, one manager from the oil and gas sector told us that diversifying a supply base "with tier-2 and 3 back up options to tier-1 suppliers" was the preferable route to create redundancies rather than adding

\begin{tabular}{|c|c|c|c|}
\hline $\begin{array}{l}\text { DV } \\
\text { Year }\end{array}$ & $\begin{array}{l}\Delta \text { in-degree centrality } \\
2010\end{array}$ & $\begin{array}{l}\Delta \text { out-degree centrality } \\
2010\end{array}$ & $\begin{array}{l}\Delta \text { ego network density } \\
2010\end{array}$ \\
\hline Treatment & $-1.145(0.772)$ & $-0.474(0.466)$ & $-0.216(0.320)$ \\
\hline Constant & $0.026(0.460)$ & $1.553^{* * * *}(0.375)$ & $-0.200(0.131)$ \\
\hline$R$-squared & 0.014 & 0.007 & 0.003 \\
\hline Observations & 152 & 152 & 152 \\
\hline \multicolumn{4}{|c|}{$\begin{array}{l}\text { Note(s): Robust standard errors in parenthesis } \\
\text { * }_{* * *} p<0.001\end{array}$} \\
\hline
\end{tabular}

Table 5.

Parallel trend in the pre-disruption phase 
suppliers. Managers from both the fast-moving consumer goods and oil and gas sectors emphasized the importance of collaborative relationships in responding to disruptions. Such relationships are harder to establish and nurture when their supply network is complex as significant effort and resources are needed just maintaining it.

While our results support the complexity perspective, it may be that the complexity and redundancy perspectives are complementary rather than conflicting and their value is evident in different stages of the business environment. The redundancy may be more effective in periods of growth, to provide flexibility and support this growth. Yet, during periods of decline, the complexity of managing all these redundant resources may overwhelm its benefits. Identifying precise reasons for these changes would be an interesting avenue for future study.

Our findings also suggest that the firms affected by the earthquake have reduced numbers of customers compared to the firms that did not report disruptions. The driving forces of the post-disruption changes on the customer network are likely to be fundamentally different from those of the supplier network and may require different responses from the focal firm. The firms that experienced catastrophic supply chain disruptions do not have an incentive to deliberately decrease the number of customers and risk losing additional sales opportunities. Rather, the reduction in the post-disruption number of customers is likely to be driven largely by the existing and potential customers' efforts to reduce complexity in their own supply networks. As a part of their own supply chain risk management strategies, for example, customers of firms that experienced severe supply chain disruptions may not retain those affected firms as suppliers (Polyviou et al., 2018). Similarly, potential customers may also be reluctant to establish new buyer-supplier relationships with the firms that experienced severe supply chain disruptions. Finally, the company-wide recovery efforts by the focal firm impacted by a severe supply chain disruption often require significant resource reprioritization (Ambulkar et al., 2015; Bode et al., 2011). This could result in a reduction of resources available for attracting new customers.

Our analysis also provides empirical evidence that firms that are impacted by major supply chain disruptions tend to have reduced levels of post-disruption ego network density compared with those unaffected by the disruptions. Past literature has considered the performance implications of high ego network density for focal firms. For instance, buying firms can obtain operational benefits through the suppliers that are interconnected in the form of access to additional resources or information pooling and sharing (Choi and $\mathrm{Wu}, 2009$; Wu and Choi, 2005). For this reason, some buying firms are known for actively encouraging connections between their suppliers (Dubois and Fredriksson, 2008; Wu and Choi, 2005) or creating ties with lower-tier suppliers (Chae et al., 2019; Choi and Linton, 2011) increasing the ego network density in their supply networks. However, it has also been suggested that an increase in the ego network density may have detrimental results; interconnections among customers may negatively influence suppliers' profitability (Kim, 2017). In the context of supply chain resilience, connections between the supply network partners could increase the likelihood of a disruption being indirectly propagated to the buying firm and bring additional coordination challenges in the network-wide recovery efforts (Choi and Krause, 2006; Han and Shin, 2016; Scheibe and Blackhurst, 2018).

Our findings imply that, after major disruptions, buying firms and their customers may prefer maintaining lower levels of ego network density in their supply networks, realizing the challenges associated with high levels of interdependencies in managing supply chain risks. An alternative body of the supply chain risk and resilience literature suggests that close relationships among partners would be useful in responding to catastrophic supply chain disruptions since they generate social capital for network-level sense-making and resource mobilization (Olcott and Oliver, 2014; Ambulkar et al., 2015). Our results do not support this view. Similar to the results for the centrality measures, our findings provide empirical
Catastrophic supply chain disruptions 
IJOPM 41,6

\section{8}

support that, after a catastrophic disruption, firms face lower supply network complexity in the form of a decreased level of ego network density compared to unaffected firms.

To summarize, this paper contributes to social network theory by shedding light on one of the least explored areas of social network theory, namely the dynamics and patterns of network change by providing empirical evidence of the changes in the supply networks of affected firms in the form of reduced complexity and possible explanations of these changes.

\subsection{Managerial implications}

Our results draw managers' attention to two issues: First, supply network complexity, which has some advantages during business as usual, may become an impediment during times of crisis. Given that crises, particularly catastrophic events such as natural disasters, are increasing at an alarming rate (Sodhi, 2016), striking a balance between these two states will become an ever-present challenge. Second, our results show that companies are finding themselves with a changed supply network after catastrophic disruptions. Disentangling the internal and external drivers of this change can help managers anticipate and respond more effectively to the changes after the disruption. Given the devastating effects of such disruptions, it is easy to understand why our focus until now has been more on the antecedents of these disruptions. We now invite managers to start reflecting on the structural changes in supply networks after disruptions.

Companies that choose to maintain a large number of supply chain partners do so because the scale determines (1) the resources and knowledge available to them (Bellamy et al., 2014; Borgatti and Li, 2009; Kim et al., 2011; Provan et al., 2007). Similarly, some buying firms encourage their supply chain partners to connect (Dubois and Fredriksson, 2008; Wu and Choi, 2005) since such interconnectedness could potentially support the development of trust, reciprocity and shared identities across the network (Granovetter, 1992; Gulati et al., 2000; Lazarrini et al., 2001). Such ties and buffers can be valuable when there are fewer and less severe disruptions. However, the subsequent complexity can significantly slow down firms' effective response to major disruptions. If this is the case, managers will reassess their position after such disruptions and simplify their supply network, which is in line with what we see in our results.

However, there is also the question of whether some of these changes are imposed by the firm's partners and the external business environment. Depending on the impact of these external drivers, managers should at least be aware of the changes that will be imposed on their supply networks and ideally have drawn up contingency plans for these new challenges, as shown by our results.

In summary, managers face the difficult question of how to balance supply network needs during normal business cycles with those experienced during disruptions. While striking an optimal balance is going to be difficult, given the very dynamic nature of the context, awareness of the different realities is the first step in preparing for and managing the impact of supply chain disruptions.

\subsection{Limitations and future research}

This study is based on the supply chain disruptions caused by one major natural disaster, the 2011 Tōhoku earthquake and tsunami. As one of the first empirical attempts to examine the impact of catastrophic supply chain disruptions on supply network structures, we chose the "single largest and broadest natural disaster in recent times" (Sheffi, 2015, p. ix) as our empirical setting. Nevertheless, the impact of this event was largely limited to Japanese firms. Although Japanese firms provide a unique, ideal context characterized by interdependent ties and dense networks (Lazzarini et al., 2001; Ouchi, 1980), the patterns of network change after supply chain disruptions could be different in other national contexts. 
Moreover, natural disasters are one of the many causes of supply chain disruptions. Therefore, we call for more future studies that investigate the impact of supply chain disruptions on supply network structural changes under broader conditions including diverse national contexts and different sources of supply chain disruption, such as trade conflicts and epidemics.

We also note that our inter-firm network data do not provide the lists of all customers and suppliers of the focal firms and the information on what products are exchanged between firms. Due to these reasons, we focused on more immediate, ego network structural changes and had limited implications for multi-tier level changes. Future studies should aim for investigating the structural changes of multi-tier supply networks after catastrophic supply chain disruptions.

Finally, although we provide evidence on how supply network structures change after major supply chain disruptions, the performance implications of those changes remain ambiguous. Future research could study how the supply network structural changes made after supply chain disruptions relate to the post-disruption resilience of those supply networks.

\section{References}

Adler, P.S. and Kwon, S.W. (2002), "Social capital: prospects for a new concept", Academy of Management Review, Vol. 27 No. 1, pp. 17-40.

Ahuja, G. (2000), "Collaboration networks, structural holes, and innovation: a longitudinal study", Administrative Science Quarterly, Vol. 45 No. 3, pp. 425-455.

Almeida, H., Campello, M., Laranjeira, B. and Weisbenner, S. (2012), "Corporate debt maturity and the real effects of the 2007 credit crisis", Critical Finance Review, Vol. 1 No. 1, pp. 3-58.

Ambulkar, S., Blackhurst, J. and Grawe, S. (2015), "Firm's resilience to supply chain disruptions: scale development and empirical examination”, Journal of Operations Management, Vol. 33 No. 34, pp. 111-122.

Autry, C.W. and Griffis, S.E. (2008), "Supply chain capital: the impact of structural and relational linkages on firm execution and innovation", Journal of Business Logistics, Vol. 29 No. 1, pp. 157-173.

Barley, S. (1986), "Technology as an occasion for structuring: evidence from observations of CT scanners and the social order of radiology departments", Administrative Science Quarterly, Vol. 31 No. 1, pp. 78-108.

Basole, R.C. and Bellamy, M.A. (2014), "Supply network structure, visibility, and risk diffusion: a computational approach", Decision Sciences, Vol. 45 No. 4, pp. 753-789.

Bellamy, M.A., Ghosh, S. and Hora, M. (2014), "The influence of supply network structure on firm innovation”, Journal of Operations Management, Vol. 32 No. 6, pp. 357-373.

Blackhurst, J., Dunn, K.S. and Craighead, C.W. (2011), "An empirically derived framework of global supply resiliency”, Journal of Business Logistics, Vol. 32 No. 4, pp. 374-391.

Bode, C. and Wagner, S.M. (2015), "Structural drivers of upstream supply chain complexity and the frequency of supply chain disruptions", Journal of Operations Management, Vol. 36, pp. 215-228.

Bode, C., Wagner, S.M., Petersen, K.J. and Ellram, L.M. (2011), "Understanding responses to supply chain disruptions: insights from information processing and resource dependence perspectives", Academy of Management Journal, Vol. 54 No. 4, pp. 833-856.

Bonacich, P. (1972), "Factoring and weighting approaches to status scores and clique identification", Journal of Mathematical Sociology, Vol. 2 No. 1, pp. 113-120.

Borgatti, S.P. and Li, X. (2009), "On social network analysis in a supply chain context", Journal of Supply Chain Management, Vol. 45 No. 2, pp. 5-22.
Catastrophic supply chain disruptions 
IJOPM 41,6

Borgatti, S.P. and Ofem, B. (2010), "Overview: social network theory and analysis", Social Network Theory and Educational Change, Harvard Press, Cambridge, MA, pp. 17-29.

Burkhardt, M.E. and Brass, D.J. (1990), "Changing patterns or patterns of change: the effects of a change in technology on social network structure and power", Administrative Science Quarterly, Vol. 35 No. 1, pp. 104-127.

Burt, R.S. (2004), "Structural holes and good ideas", American Journal of Sociology, Vol. 110 No. 2, pp. 349-399.

Chae, S., Lawson, B., Kull, T.J. and Choi, T.Y. (2019), "To insource or outsource the sourcing? A behavioral investigation of the multi-tier sourcing decision", International Journal of Operations and Production Management, Vol. 39 No. 3, pp. 385-405.

Chae, S., Yan, T. and Yang, Y. (2020), "Supplier innovation value from a buyer-supplier structural equivalence view: evidence from the PACE awards in the automotive industry", Journal of Operations Management, Vol. 66 Nos 7-8, pp. 820-838.

Chaturvedi, A. and Martínez-de-Albéniz, V. (2011), "Optimal procurement design in the presence of supply risk”, Manufacturing and Service Operations Management, Vol. 13 No. 2, pp. 227-243.

Choi, T.Y. and Kim, Y. (2008), "Structural embeddedness and supplier management: a network perspective”, Journal of Supply Chain Management, Vol. 44 No. 4, pp. 5-13.

Choi, T.Y. and Krause, D.R. (2006), "The supply base and its complexity: implications for transaction costs, risks, responsiveness, and innovation", Journal of Operations Management, Vol. 24 No. 5 , pp. 637-652.

Choi, T.Y. and Linton, T. (2011), “Don't let your supply chain control your business”, Harvard Business Review, Vol. 89 No. 12, pp. 112-117.

Choi, T.Y. and Wu, Z. (2009), "Triads in supply networks: theorizing buyer-supplier-supplier relationships", Journal of Supply Chain Management, Vol. 45 No. 1, pp. 8-25.

Choi, T.Y., Dooley, K.J. and Rungtusanatham, M. (2001), "Supply networks and complex adaptive systems: control versus emergence", Journal of Operations Management, Vol. 19 No. 3, pp. 351-366.

Chowdhury, M.M.H. and Quaddus, M. (2017), "Supply chain resilience: conceptualization and scale development using dynamic capability theory", International Journal of Production Economics, Vol. 188, pp. 185-204.

Chowdhury, M.M.H., Quaddus, M. and Agarwal, R. (2019), "Supply chain resilience for performance: role of relational practices and network complexities", Supply Chain Management: International Journal, Vol. 24 No. 5, pp. 659-676.

Craighead, C.W., Blackhurst, J., Rungtusanatham, M.J. and Handfield, R.B. (2007), "The severity of supply chain disruptions: design characteristics and mitigation capabilities", Decision Sciences, Vol. 38 No. 1, pp. 131-156.

Dong, M.C., Liu, Z., Yu, Y. and Zheng, J.H. (2015), "Opportunism in distribution networks: the role of network embeddedness and dependence", Production and Operations Management, Vol. 24 No. 10, pp. 1657-1670.

Dooley, K., Pathak, S., Kull, T., JohnsonWu, J.Z. and Rabinovich, E. (2019), "Process network modularity, commonality, and greenhouse gas emissions", Journal of Operations Management, Vol. 65 No. 2, pp. 93-113.

Doreian, P. (1986), "On the evolution of group and network structure II: structures within structure", Social Networks, Vol. 8 No. 1, pp. 33-64.

Dubois, A. and Fredriksson, P. (2008), "Cooperating and competing in supply networks: making sense of a triadic sourcing strategy", Journal of Purchasing and Supply Management, Vol. 14 No. 3, pp. 170-179.

FactSet (2021), "FactSet supply chain relationships", available at: https:/open.factset.com/products/ factset-supply-chain-relationships/en-us?hsCtaTracking $=\mathrm{d} 75 f 5 \mathrm{e} 67-4 \mathrm{e} 4 \mathrm{~b}-4352-8 \mathrm{e} 94$ 456617a858df\% 7C09878490-9243-4890-9f7a-20a20e4fe135 (accessed 29 January 2021). 
Giannoccaro, I., Nair, A. and Choi, T.Y. (2018), "The impact of control and complexity on supply network performance: an empirically informed investigation using NK simulation analysis", Decision Sciences, Vol. 49 No. 4, pp. 625-659.

Granovetter, M. (1992), "Economic institutions as social constructions: a framework for analysis", Acta Sociologica, Vol. 35 No. 1, pp. 3-11.

Granovetter, M.S. (1973), "The strength of weak ties”, American Journal of Sociology, Vol. 78 No. 6, pp. 1360-1380.

Granovetter, M.S. (1983), "The strength of weak ties: a network theory revisited", Sociological Theory, Vol. 1 No. 5, pp. 201-233.

Gulati, R. and Gargiulo, M. (1999), "Where do interorganizational networks come from?", American Journal of Sociology, Vol. 104 No. 5, pp. 1439-1493.

Gulati, R., Nohria, N. and Zaheer, A. (2000), "Strategic networks", Strategic Management Journal, Vol. 21 No. 3, pp. 203-215.

Gunessee, S. and Subramanian, N. (2020), "Ambiguity and its coping mechanisms in supply chains lessons from the Covid-19 pandemic and natural disasters", International Journal of Operations and Production Management, Vol. 40 Nos 7/8, pp. 1201-1223.

Han, J. and Shin, K. (2016), "Evaluation mechanism for structural robustness of supply chain considering disruption propagation", International Journal of Production Research, Vol. 54 No. 1, pp. 135-151.

Handfield, R.B., Gary, G. and Burns, L. (2020), "Coronavirus, tariffs, trade wars and supply chain evolutionary design", International Journal of Operations and Production Management, Vol. 40 No. 10, pp. 1649-1660.

Hearnshaw, E.J. and Wilson, M.M. (2013), "A complex network approach to supply chain network theory", International Journal of Operations and Production Management, Vol. 33 No. 4, pp. $442-469$.

Hendricks, K.B. and Singhal, V.R. (2005), "An empirical analysis of the effect of supply chain disruptions on long-run stock price performance and equity risk of the firm", Production and Operations Management, Vol. 14 No. 1, pp. 35-52.

Janssen, M., Bodin, Ö, Anderies, J., Elmqvist, T., Ernstson, H., McAllister, R., Olson, P. and Ryan, P. (2006), "Toward a network perspective of the study of resilience in social-ecological systems", Ecology and Society, Vol. 11 No. 1.

Johnson, N., Elliott, D. and Drake, P. (2013), "Exploring the role of social capital in facilitating supply chain resilience", Supply Chain Management: International Journal, Vol. 18 No. 3, pp. 324-336.

Kamalahmadi, M. and Parast, M.M. (2016), "A review of the literature on the principles of enterprise and supply chain resilience: major findings and directions for future research", International Journal of Production Economics, Vol. 171 No. 1, pp. 16-133.

Kauffman, S. and Levin, S. (1987), "Towards a general theory of adaptive walks on rugged landscapes", Journal of Theoretical Biology, Vol. 128 No. 1, pp. 11-45.

Kauffman, S., Pathak, S.D., Sen, P.K. and Choi, T.Y. (2018), "Jury rigging and supply network design: evolutionary 'Tinkering' in the presence of unknown-unknowns", Journal of Supply Chain Management, Vol. 54 No. 1, pp. 51-63.

Kim, Y.H. (2017), "The effects of major customer networks on supplier profitability", Journal of Supply Chain Management, Vol. 53 No. 1, pp. 26-40.

Kim, Y., Choi, T.Y., Yan, T. and Dooley, K. (2011), "Structural investigation of supply networks: a social network analysis approach", Journal of Operations Management, Vol. 29 No. 3, pp. 194-211.

Kim, Y., Chen, Y.S. and Linderman, K. (2015), "Supply network disruption and resilience: a network structural perspective", Journal of Operations Management, Vol. 33, pp. 43-59. 
IJOPM 41,6
Kleindorfer, P.R. and Saad, G.H. (2005), "Managing disruption risks in supply chains", Production and Operations Management, Vol. 14 No. 1, pp. 53-68.

Koka, B.R., Madhavan, R. and Prescott, J.E. (2006), "The evolution of interfirm networks: environmental effects on patterns of network change", Academy of Management Review, Vol. 31 No. 3, pp. 721-737.

Koka, B.R. and Prescott, J.E. (2002), "Strategic alliances as social capital: a multidimensional view", Strategic Management Journal, Vol. 23 No. 9, pp. 795-816.

Krause, D.R., Handfield, R.B. and Tyler, B.B. (2007), "The relationships between supplier development, commitment, social capital accumulation and performance improvement", Journal of Operations Management, Vol. 25 No. 2, pp. 528-545.

Lazzarini, S.G., Chaddad, F.R. and Cook, M.L. (2001), "Integrating supply chain and network analyses: the study of netchains", Journal on Chain and Network Science, Vol. 1 No. 1, pp. 7-22.

Lee, H.L., Padmanabhan, V. and Whang, S. (1997), "Information distortion in a supply chain: the bullwhip effect", Management Science, Vol. 43 No. 4, pp. 546-558.

Levinthal, D.A. (1997), “Adaptation on rugged landscapes”, Management Science, Vol. 43 No. 7 , pp. 934-950.

Li, S.X. and Rowley, T.J. (2002), "Inertia and evaluation mechanisms in interorganizational partner selection: syndicate formation among US investment banks", Academy of Management Journal, Vol. 45 No. 6, pp. 1104-1119.

Li, G., Yang, H., Sun, L., Ji, P. and Feng, L. (2010), "The evolutionary complexity of complex adaptive supply networks: a simulation and case study", International Journal of Production Economics, Vol. 124 No. 2, pp. 310-330.

Lu, G. and Shang, G. (2017), "Impact of supply base structural complexity on financial performance: roles of visible and not-so-visible characteristics", Journal of Operations Management, Vol. 53, pp. 23-44.

Madhavan, R., Koka, B.R. and Prescott, J.E. (1998), "Networks in transition: how industry events (re) shape interfirm relationships", Strategic Management Journal, Vol. 19 No. 5, pp. 439-459.

Nahapiet, J. and Ghoshal, S. (1998), "Social capital, intellectual capital, and the organizational advantage", Academy of Management Review, Vol. 23 No. 2, pp. 242-266.

Nair, A., Yan, T., Ro, Y.K., Oke, A., Chiles, T.H. and Lee, S.Y. (2016), "How environmental innovations emerge and proliferate in supply networks: a complex adaptive systems perspective", Journal of Supply Chain Management, Vol. 52 No. 2, pp. 66-86.

Nohria, N. and Eccles, R.G. (1992), Networks and Organizations: Structure, Form, and Action, Harvard Business School Press, Cambridge, MA.

Olcott, G. and Oliver, N. (2014), "Social capital, sensemaking, and recovery: Japanese companies and the 2011 earthquake", California Management Review, Vol. 56 No. 2, pp. 5-22.

Ouchi, W.G. (1980), "Markets, bureaucracies, and clans”, Administrative Science Quarterly, Vol. 25 No. 1, pp. 129-141.

Park, Y., Hong, P. and Roh, J.J. (2013), "Supply chain lessons from the catastrophic natural disaster in Japan”, Business Horizons, Vol. 56 No. 1, pp. 75-85.

Park, H., Bellamy, M.A. and Basole, R.C. (2018), "Structural anatomy and evolution of supply chain alliance networks: a multi-method approach", Journal of Operations Management, Vol. 63, pp. 79-96.

Pathak, S.D., Day, J.M., Nair, A., Sawaya, W.J. and Kristal, M.M. (2007), "Complexity and adaptivity in supply networks: building supply network theory using a complex adaptive systems perspective", Decision Sciences, Vol. 38 No. 4, pp. 547-580.

Perrow, C. (1984), Normal Accidents: Living with High Risk Technologies, Basic Books, New York, NY.

Pettit, T.J., Fiksel, J. and Croxton, K.L. (2010), "Ensuring supply chain resilience: development of a conceptual framework", Journal of Business Logistics, Vol. 31 No. 1, pp. 1-21. 
Pettit, T.J., Croxton, K.L. and Fiksel, J. (2013), "Ensuring supply chain resilience: development and implementation of an assessment tool", Journal of Business Logistics, Vol. 34 No. 1, pp. 46-76.

Pettit, T.J., Croxton, K.L. and Fiksel, J. (2019), "The evolution of resilience in supply chain management: a retrospective on ensuring supply chain resilience", Journal of Business Logistics, Vol. 40 No. 1, pp. 56-65.

Polyviou, M., Rungtusanatham, M.J., Reczek, R.W. and Knemeyer, A.M. (2018), "Supplier non-retention post disruption: what role does anger play?", Journal of Operations Management, Vol. 61, pp. 1-14.

Powell, W.W., White, D.R., Koput, K.W. and Owen-Smith, J. (2005), "Network dynamics and field evolution: the growth of interorganizational collaboration in the life sciences", American Journal of Sociology, Vol. 110 No. 4, pp. 1132-1205.

Provan, K.G., Fish, A. and Sydow, J. (2007), "Interorganizational networks at the network level: a review of the empirical literature on whole networks", Journal of Management, Vol. 33 No. 3, pp. 479-516.

Rice, J.B. and Caniato, F. (2003), "Building a secure and resilient supply network", Supply Chain Management Review, Vol. 7 No. 5, pp. 22-30.

Rosenbaum, P.R. and Rubin, D.B. (1983), "The central role of the propensity score in observational studies for causal effects", Biometrika, Vol. 70 No. 1, pp. 41-55.

Rowley, T., Behrens, D. and Krackhardt, D. (2000), "Redundant governance structures: an analysis of structural and relational embeddedness in the steel and semiconductor industries", Strategic Management Journal, Vol. 21 No. 3, pp. 369-386.

Sawaya, W., Pathak, S., Day, J. and Kristal, M. (2015), "Sensing abnormal resource flow using adaptive limit process charts in a complex supply network", Decision Sciences, Vol. 46 No. 5, pp. 961-979.

Scheibe, K.P. and Blackhurst, J. (2018), "Supply chain disruption propagation: a systemic risk and normal accident theory perspective", International Journal of Production Research, Vol. 56 Nos 1-2, pp. 43-59.

Shao, B., Shi, Z., Choi, T.Y. and Chae, S. (2018), "A data-analytics approach to identifying hidden critical suppliers in supply networks: development of nexus supplier index", Decision Support Systems, Vol. 114, pp. 37-48.

Sheffi, Y. (2015), The Power of Resilience: How the Best Companies Manage the Unexpected, MIT Press, Cambridge, MA.

Sheffi, Y. and Rice, J.B. (2005), "A supply chain view of the resilient enterprise", MIT Sloan Management Review, Vol. 47 No. 1, pp. 41-48.

Shih, W. (2020), "Global supply chains in a post-pandemic world", Harvard Business Review, Vol. 98 No. 5 , pp. 82-89.

Simon, H. (1962), "The architecture of complexity", Proceedings of the American Philosophical Society, Vol. 106 No. 6, pp. 467-482.

Skilton, P.F. and Bernardes, E. (2015), "Competition network structure and product market entry", Strategic Management Journal, Vol. 36 No. 11, pp. 1688-1696.

Sodhi, M.S. (2016), "Natural disasters, the economy and population vulnerability as a vicious cycle with exogenous hazards", Journal of Operations Management, Vol. 45, pp. 101-113.

Son, B.G., Kocabasoglu-Hillmer, C. and Roden, S. (2016), "A dyadic perspective on retailer-supplier relationships through the lens of social capital”, International Journal of Production Economics, Vol. 178, pp. 120-131.

Suitor, J.J., Wellman, B. and Morgan, D.L. (1997), "It's about time: how, why, and when networks change", Social Networks, Vol. 19 No. 1, pp. 1-7.

Uzzi, B. (1996), "The sources and consequences of embeddedness for the economic performance of organizations: the network effect", American Sociological Review, Vol. 61 No. 4, pp. 674-698.
Catastrophic

supply chain disruptions 
IJOPM 41,6

Van Hoek, R. (2020), "Research opportunities for a more resilient post-COVID-19 supply chain-closing the gap between research findings and industry practice", International Journal of Operations and Production Management, Vol. 40 No. 4, pp. 341-355.

Venkatraman, N. and Lee, C.-H. (2004), "Preferential linkage and network evolution: a conceptual model and empirical test in the US video game sector", Academy of Management Journal, Vol. 47 No. 6, pp. 876-892.

Wagner, S.M. (2012), “Tapping supplier innovation”, Journal of Supply Chain Management, Vol. 48 No. 2, pp. 37-52.

Wagner, S.M. and Bode, C. (2006), "An empirical investigation into supply chain vulnerability", Journal of Purchasing and Supply Management, Vol. 12 No. 6, pp. 301-312.

Wagner, S.M. and Bode, C. (2008), "An empirical examination of supply chain performance along several dimensions of risk", Journal of Business Logistics, Vol. 29 No. 1, pp. 307-325.

Wagner, S.M. and Neshat, N. (2010), "Assessing the vulnerability of supply chains using graph theory", International Journal of Production Economics, Vol. 126 No. 1, pp. 121-129.

Walker, G., Kogut, B. and Shan, W. (1997), "Social capital, structural holes and the formation of an industry network", Organization Science, Vol. 8 No. 2, pp. 109-125.

Wang, Y., Li, J., Wu, D. and Anupindi, R. (2020), "When ignorance is not bliss: an empirical analysis of subtier supply network structure on firm risk", Management Science, Articles in advance.

Wiedmer, R., Rogers, Z.S., Polyviou, M., Mena, C. and Chae, S. (2021), "The dark and bright sides of complexity: a dual perspective on supply network resilience", Journal of Business Logistics, Early view.

Wu, Z. and Choi, T.Y. (2005), "Supplier-supplier relationships in the buyer-supplier triad: building theories from eight case studies", Journal of Operations Management, Vol. 24 No. 1, pp. 27-52.

Yan, T., Yang, Y., Dooley, K. and Chae, S. (2020), "Trading-off innovation novelty and information protection in supplier selection for a new product development project: supplier ties as signals", Journal of Operations Management, Vol. 66 Nos 7-8, pp. 933-957.

Zaheer, A. and Soda, G. (2009), "Network evolution: the origins of structural holes", Administrative Science Quarterly, Vol. 54 No. 1, pp. 1-31.

\section{Corresponding author}

Sangho Chae can be contacted at: s.chae@tilburguniversity.edu

For instructions on how to order reprints of this article, please visit our website:

www.emeraldgrouppublishing.com/licensing/reprints.htm

Or contact us for further details: permissions@emeraldinsight.com 